Chapter 9

\title{
Maternal Influenza: Infection, Vaccination, and Compelling Questions
}

\author{
Jill M. Manske
}

Additional information is available at the end of the chapter

http://dx.doi.org/10.5772/64368

\begin{abstract}
Influenza presents a significant risk for increased morbidity and mortality to pregnant women and infants based on evidence from previous influenza pandemics, seasonal epidemics, and the recent H1N1 pandemic. Since 2004, influenza vaccine has been recommended for pregnant women during any trimester of pregnancy to reduce this risk. This chapter presents an overview of influenza risks associated with pregnancy as well as a review of our current understanding of vaccine effectiveness in pregnant women, neonates, and young infants. In addition, some of the current compelling questions related to influenza risk and prevention across all trimesters of pregnancy are explored.
\end{abstract}

Keywords: influenza vaccine, pregnancy, effectiveness, maternal immunization

\section{Introduction}

Influenza is a highly contagious, acute respiratory infection (ARI). Each year, it is estimated that $5-10 \%$ of adults and $20-30 \%$ of children worldwide will become infected with influenza [1]. Pregnant women and infants are at particular risk for influenza. Influenza infection during pregnancy or during the first 6 months of life is a substantial cause of morbidity. Prevention of influenza in these populations is of global health importance. 


\section{Maternal influenza}

Pregnant women are considered a high-risk group for serious illness and complications from influenza. While annual influenza incidence rates in pregnant women are similar to those of nonpregnant women [2-4], influenza infection is associated with increased morbidity and mortality in this subpopulation, with pregnant women having an increased risk of influenzaattributed hospitalizations compared to nonpregnant women [4, 5]. Most likely this is associated with the interaction of the infection with the physiologic and immunologic changes that occur during pregnancy.

Pregnancy-associated changes such as decreased lung capacity, reduced tidal volume, and increased cardiac output likely reduce the capacity of the respiratory and cardiac system to respond to the stress of influenza infection $[2,6]$. In addition, during pregnancy there is a progressive suppression of cellular (T-cell mediated) immunity. While this immune suppression serves to protect the developing fetus from maternal cytotoxic T-cell immunity, it can impair the maternal response to viral infections such as influenza [7-11].

The combination of these factors contributes to an increased risk of negative outcomes from influenza infection. If respiratory disease develops, especially during the later stages of pregnancy, it can lead to high morbidity among the pregnant women [6, 12-14]. In a study of hospital admissions records of women admitted between 1994 and 2000 with respiratory conditions during pregnancy, the hospitalization rate was 150/100,000, an admission rate considerably higher than that of nonpregnant women $(17 / 100,000)$ and corresponding to the rate for people aged 65-69 [5]. Healthy pregnant women ages 20-34 were estimated to be 18 times more likely to be hospitalized for influenza than their nonpregnant peers [5].

While hospitalization rates are increased in all trimesters of pregnancy $[4,15,16]$, they are the highest during the third trimester [5, 14, 16-18]. Likewise, there is a strong association of maternal morbidity with this trimester of pregnancy. In a 2003 study, Hartert et al. showed that cardiovascular hospitalization during influenza season increased with each trimester, nearly threefold higher by the third trimester compared to the first trimester [18]. In a study of 8323 healthy pregnant and postpartum women, Lindsay et al. found that the strength of association between influenza exposure and influenza-like illness (ILI) increased as the stage of pregnancy progressed, reporting an odds ratio (OR) of 1.12 (CI, 0.79-1.59) during the first trimester, 1.30 (CI, 0.97-1.73) during the second trimester, and 1.84 (CI, 1.31-2.59) for the third trimester [14]. Other studies have reported that by the third trimester, healthy pregnant women with no comorbidity have the same risk for ILI-associated hospitalization as nonpregnant women with chronic or comorbid conditions $[4,5]$.

Pregnant women with comorbid conditions such as asthma, diabetes, heart disease, or chronic obstructive pulmonary disease are even more likely to be hospitalized than are pregnant women without chronic conditions [5, 14, 16-18]. Neuzil et al. reported event rates for influenza for low-risk women of 3, 6, and 10 per 10,000 women months in the first, second, and third trimesters, respectively. The event rate in nonpregnant women was 2 per 10,000 women months. Among women with chronic comorbid conditions, rates of 31, 16, and 21 per 10,000 women months were observed during these trimesters, respectively [4]. 
While considerable data demonstrate increased morbidity and hospitalization from seasonal influenza in pregnant women, mortality appears to be rare in healthy pregnant women during non-pandemic seasons [7, 19, 20]. A study of seasonal influenza among pregnant women over an 8-year period reported an average of five deaths per year and a mean mortality ratio of 2.9 per million live births [21]. However, during pandemics, influenza infection presents a significant increased risk of both morbidity and mortality in pregnant women.

For example, during the pandemic of 1918, pneumonia was reported in $50 \%$ of previously healthy pregnant women, leading to case-fatality rates of over 50\% [22-26]. In the 1957 pandemic, $50 \%$ of the women of childbearing age who died of influenza were pregnant. Furthermore, $10 \%$ of all influenza deaths during this pandemic occurred in pregnant women, with the majority occurring during the third trimester [23, 24].

Increased rates of morbidity and mortality in pregnant women also were observed more recently during the 2009 influenza A(H1N1)pdm09 pandemic. In fact, the first reported death of an adult in the United States during this pandemic was a pregnant woman [27]. Of the 45 deaths reported early in the pandemic, $6(13.3 \%)$ were pregnant women, all of whom developed viral pneumonia and respiratory distress syndrome [27-29].

A study of pregnant US women with confirmed or probable influenza during the first month of the outbreak reported $11 / 34$ cases (32.4\%) resulted in hospitalization-admissions rates four times higher than those in the general population [30]. Deaths were reported in all three trimesters and were independent of preexisting risk factors. In a California study, pregnant women who were hospitalized with or died from $\mathrm{pH} 1 \mathrm{~N} 1$ were less likely than nonpregnant women to have a predisposing or comorbid medical condition [31].

A review of published studies following the 2009 pandemic documented that pregnant women were disproportionately represented among hospitalizations, ICU admissions, and deaths. The 120 papers that were included in the review reported 3110 pregnant women from 29 countries with $\mathrm{A}(\mathrm{H} 1 \mathrm{~N} 1)$ pdm09 influenza infection, including 1625 (52.3\%) who were hospitalized with 2009 H1N1, of whom 378 (23.3\%) were admitted to an ICU and 130 (8\%) died [32]. Pooling the data from all of the studies included in the review, the authors reported that pregnant women, who represent approximately $1 \%$ of the population of United States and Australia, accounted for $6.3 \%$ of hospitalizations, $5.9 \%$ of ICU admissions, and $5.7 \%$ of deaths [32].

Using data from the Centers for Disease Control (CDC) and the Pregnancy Mortality Surveillance System, Callaghan et al. estimated the total burden of pregnancy-related mortality resulting from the 2009 to 2010 pandemic. Confirmed and possible deaths resulting from $\mathrm{A}(\mathrm{H} 1 \mathrm{~N} 1) \mathrm{pdm} 09$ infection represented the leading cause of pregnancy-related mortality in the United States between the months of April 2009 and June 2010. Of 915 total pregnancy-related deaths during this period, $12 \%$ of pregnancy-related deaths were attributed to influenza, 75 (8.2\%) classified as confirmed influenza A(H1N1)pdm09 deaths, and 34 (3.7\%) classified as possible influenza infection deaths [33]. The authors calculated the pregnancy-related morality ratio for confirmed and possible influenza deaths at 2.2 per 100,000 live births. This represents a significant burden of mortality. The number of deaths (109) during the 2009-2010 influenza 
season was 20 times greater than the mean number (5) of annual possible influenza deaths reported in a 1998-2005 cohort of pregnancy-related deaths in non-pandemic years [33].

Infants born to influenza-infected women during the pandemic also experienced increased risks of poor clinical outcomes, mostly due to preterm birth. Reports of preterm birth rates ranged from 15 to $30 \%$ among infected women [32, 34-36]. Infection with A(H1N1)pdm09 was associated with increased risk of cesarean delivery [32]. In most cases, cesarean delivery was an attempt to improve worsening maternal status rather than out of concern for the infant [32]. Siston et al. reported a cesarean delivery rate of 58\% in pregnant women with 2009 H1N1 compared to a baseline cesarean rate of $30.5 \%$ [32, 34, 37]. While cesarean deliveries were commonly described, it is likely that this rate was over-reported, since many of the studies reported only severely affected women. Many deliveries were emergencies and performed outside of controlled operating room settings, indicating the urgent nature of these deliveries and the critical status of the women [32].

\section{Influenza infection and fetal development}

While there is no clear consensus on transplacental transmission of influenza virus or direct viral effects on the fetus [2], the spread of virus beyond the respiratory tract during acute infection is unusual, and vertical transmission, although documented [38-40], appears to be rare [41, 42]. However, even in the absence of vertical transmission, adverse fetal effects can occur, most likely due to the systemic maternal immune response to the infection [43, 44]. Studies have documented inflammatory responses in fetal tissues in response to influenza infection. Such responses could impact the maternal-fetal interface, the placenta, or the fetus directly, leading to pregnancy loss [43]. In addition to direct damage from inflammatory responses, it is hypothesized that maternal hyperthermia can result in adverse fetal outcomes $[28,45]$. Maternal hyperthermia during the first trimester of pregnancy, regardless of the cause, has been associated with an increased risk for neural tube defects [46], while fever during labor has been associated with adverse outcomes including neonatal seizures, cerebral palsy, encephalopathy, and death [2, 47-50].

In a large population-based study of influenza infection in over 100,000 women, Hansen et al. observed an increased risk for fetal abnormalities (e.g., central nervous system malfunctions in the fetus, chromosomal abnormalities, suspected damage to the fetus from viral disease) was present in both seasonal (OR 1.53, CI, 1.19-1.95) and pandemic infections (OR 1.48, CI, 1.27-1.73) [51].

A review and meta-analysis of 33 studies published from 1953 to 2013 of first-trimester influenza exposure found that influenza exposure during the first trimester of pregnancy was associated with an increase in congenital abnormalities [adjusted odds ratio (AOR) 2.00, CI, 1.62-4.28]. Anomalies included neural tube defects [odds ratio (OR) 3.33, CI, 2.05-5.40], hydrocephaly (OR 5.74, 1.10-30.00), congenital heart defects (OR 1.56, 1.13-2.14), cleft lip (OR 3.12, CI, 2.20-4.42), digestive system anomalies (OR 1.72, CI, 1.09-2.68), and limb reduction defects (OR 2.03, CI, 1.27-3.27) [52]. A major limitation of this study concerns the fact that it 
defined influenza exposure as any reported influenza, influenza-like illness, or fever with or without clinical confirmation. The inclusion of wide clinical symptoms without laboratory confirmation of influenza likely resulted in overestimation of the number of infants exposed to influenza during gestation. It therefore cannot be determined whether congenital abnormalities were associated with general, all cause hyperthermia or whether influenza infection poses a unique and specific risk for these outcomes. Nonetheless, these observations suggest that prevention of influenza during the first trimester of pregnancy may reduce risk for congenital abnormalities.

Fetal demise is associated with influenza infection as well. Women with influenza, especially those with pneumonia, had high rates of spontaneous abortion and preterm birth, with $52 \%$ of pregnancies ending in spontaneous abortion or preterm delivery during the 1918 pandemic $[22,23,25]$.

Using a large nationwide registry, Haberg et al. examined the risk of fetal death after maternal exposure to pandemic influenza infection. The researchers found that pregnant women with a clinical diagnosis of influenza had a nearly twofold increase in the risk of fetal death (adjusted hazard ratio, $1.91 ; 95 \% \mathrm{CI}, 1.07-3.41$ ) as compared to women who were not exposed to influenza [53].

Pierce et al. assessed perinatal outcomes of maternal A(H1N1)pdm09 infection. The authors found that perinatal mortality was higher in infants born to infected women than in infants of uninfected women (39 per 1000 live births versus 7 per 1000 total births, respectively, $p=0.001$ ). This was principally explained by an increase in the rate of stillbirth (27 per 1000 total births versus 6 per 1000 total births, $p=0.001$ ) [54].

\section{Influenza infection in neonates and young infants}

Infants younger than 6 months of age are at a heightened risk for serious illness from influenza, exhibiting the highest rates of severe influenza compared to other pediatric populations [41]. This age group has higher rates of hospitalization, more prolonged ICU stays, and higher fatality rates ( 0.33 per 100,000 children) than almost any other age group [55-59]. In the United States, estimates of hospitalization rates for young infants (less than 6 months of age) range between 1.8 and 7.2 per 1000 infants, higher than reported rates of hospitalization for children up to 4 years of age ( 0.14 per 1000) [60] and people $65-80$ years of age ( $0.56-2.13$ per 1000$)$ [6063]. Childhood deaths associated with influenza are most frequent in infants during the first months of life, with mortality rates in infants 0-6 months old more than four times higher than those in older children [59].

Libster et al. [64] documented particularly high mortality rates for infants during the 2009 H1N1 pandemic in Argentina. Of 251 infants and children hospitalized with confirmed A(H1N1)pdm09 infection, 13 (5\%) died, for an overall death rate of 1.1 per 100,000 children. Infants were at particularly high risk for fatality, representing the highest death rate at 7.6 per 100,000 children. By comparison, this death rate was 10 times the reported US infant death rate during the relatively serious seasonal influenza season of 2003-2004 [59, 64]. 
Taken together, these observations highlight the impact of influenza on infants, especially the youngest, and underscore the need for prevention in this vulnerable population.

\section{Maternal influenza vaccination}

A large body of evidence collected over several decades demonstrates that pregnant women and young infants are at increased risk for complications from influenza, making control of influenza infection in these populations an important public health challenge. Influenza vaccines have been used since 1945 and currently are the primary strategy for preventing influenza infection [65].

Due to the frequent changes of the influenza viral antigens, a vaccine is formatted during the end of the previous season to include the specific antigens of the influenza strains expected to circulate in the following season, with a goal of conferring protection against the upcoming season's strains. Each year, the trivalent inactivated influenza vaccines (IIV3) are formulated to contain three viral components: two influenza A subtypes and one influenza B virus. In 2012, the US Food and Drug Administration (FDA) approved the use of a quadrivalent influenza vaccine (IIV4). The quadrivalent vaccine contains two influenza A subtypes and two influenza B subtypes. In 2009, a monovalent H1N1 vaccine was prepared because the newly recognized strain was identified too late in the season to be included in the trivalent seasonal vaccines [66].

The current inactivated influenza vaccines (IIVs) are composed of inactivated (killed) virus that has been chemically disrupted and purified to form a split-inactivated virus preparation. Such split-virus vaccines contain purified HA and NA antigens and have fewer side effects and reactions than inactivated whole virus vaccines. The IIVs currently available in the United States are split virus or subunit virus similar to the split virus [66].

The other vaccine available in the United States is a live, attenuated influenza vaccine (LAIV). This vaccine is composed of live, attenuated, cold-adapted, temperature-sensitive virus administered directly into the nasal passage. The type A and B strains of influenza in this vaccine can replicate in the nasal passages, stimulating an immune response, but cannot replicate in the lower respiratory tract [67]. While LAIV has been licensed in the United States since 2003, it is not recommended for use in pregnant women [68].

A strategy to increase the effectiveness of IIVs is the addition of adjuvants. Adjuvants are compounds that stimulate the immune system to mount a more robust and protective response to the vaccine. The most commonly used adjuvants in influenza vaccines are the oil-based compounds AS03 and MF59. Adjuvants can allow for the use of lower doses of antigen, resulting in more available doses of vaccine, which may be useful in times of high demand such as during pandemics. While adjuvanted vaccines are not approved for use in pregnant women in the United States, in Canada, and in many European countries, the pandemic vaccine was formulated with adjuvant and administered to pregnant women [69].

Vaccination of pregnant women with IIV has taken place since the 1960s. Universal recommendation for vaccinating woman at all stages of pregnancy has been recommended by the 
CDC's Advisory Committee on Immunization Practices (ACIP) since 2004 [65, 70, 71] and by the World Health Organization (WHO) since 2005 [1]. The Advisory Committee on Immunization Practices does not preferentially recommend a specific formulation-trivalent or quadrivalent - of the influenza vaccine [72]. In response to the $2009 \mathrm{H} 1 \mathrm{~N} 1$ pandemic, the WHO placed pregnant women, along with caregivers of infants younger than 6 months old, healthcare and emergency services personnel, individuals between 6 months and 24 years, and those aged 25 years or older with chronic medical conditions, in the highest priority group to receive vaccines [73].

The American College of Obstetrics and Gynecology (ACOG) considers prevention of influenza to be an "essential element of prenatal care" [74]. In full support of the ACIP recommendations, ACOG issued new guidelines in September of 2010 stating that all unvaccinated pregnant women at any gestational age be vaccinated against influenza [74].

It is well documented that the antibody $(\mathrm{Ab})$ response to influenza vaccine in pregnant women is similar to that of age-matched, nonpregnant women [75-79]. These observations support a conclusion that influenza vaccination will lead to an effective immune response in pregnant women and thereby provide an important tool in prevention of influenza in this population.

\subsection{Effectiveness of maternal influenza vaccines}

Pregnant women and neonates are high-risk groups for complications from influenza infection. Control of influenza in this population is an important public health concern. However, due in part to ethical concerns related to enrolling pregnant women in clinical studies, experimental data on influenza vaccination during pregnancy has been scarce, and the quality of the evidence is not consistently high overall [80].

Prior to 2010, there were few well-designed studies specifically addressing vaccine effectiveness in pregnant women. From 1964 to 2008, four studies specifically addressed vaccine effectiveness in pregnant women (Table 1). These studies covered eight different influenza seasons and included 51,547 pregnant women.

During a 1962-1963 outbreak of Asian influenza, Hulka measured vaccine effectiveness in pregnant women by asking immunized and nonimmunized patients if they had experienced influenza symptoms during the influenza season. While fewer immunized than unimmunized patients reported respiratory illness with fever ( $11 \%$ versus $20 \%$, respectively), there was no significant difference in reports of respiratory illness between these patients [76].

Black et al. assessed vaccine effectiveness in almost 50,000 pregnant women across five influenza seasons. Vaccine effectiveness was determined by the number of outpatient visits for ILI or hospitalization for influenza or pneumonia. Using these outcomes, the risk of medical visit for respiratory symptoms was no different between vaccinated and unvaccinated women, and hospitalization was rare in both groups [81]. Using the adjusted hazard ratios $(\mathrm{AHR}=1.151 ; \mathrm{CI}, 0.979-1.352)$ from this study, Skowronski and De Serres calculated a vaccine effectiveness of $-15 \%$ (CI, -35 to $2 \%$ ) for this study population [7]. 
In a retrospective case-control study of five influenza seasons (1995-2003), Munoz et al. estimated the potential protective effect of vaccination by recording the occurrence of acute respiratory infection (ARI) in vaccinated and unvaccinated women. The researchers reported a nonsignificant $(p=0.24)$ trend toward lower incidence of medically attended ARI in vaccinated women as compared to unvaccinated women $(22.6 \%$ of the vaccinated cohort versus $18.9 \%$ of the unvaccinated cohort) [82]. Among the women who developed ARI, the number of episodes of ARI was the same, 1.4 illnesses/person in both groups. However, there was a difference in the timing of these episodes, with $9 \%$ of the vaccinated cohort reporting ARI episodes during the peak of the influenza season, while $19 \%$ of the ARI events in the unvaccinated cohort occurred during the peak ( $p=0.01, \mathrm{CI}, 0.1-0.8)$ [82]. In this study, only three women were diagnosed with ILI, one vaccinated and two unvaccinated women, all during the peak influenza seasons of 1999-2000 and 2000-2001. These low rates of ILI as well as the small number of vaccinated women in the study population (vaccination rate was $3.5 \%$ ) are limitations of this study. Using the relative risks reported in the study, vaccine effectiveness was $-20 \%$ for ARI any time during pregnancy (CI, -59 to $9 \%$ ) and $39 \%(\mathrm{CI},-56$ to $76 \%$ ) during the peak of the influenza season [7].

\begin{tabular}{|c|c|c|c|c|}
\hline Study & $\begin{array}{l}\text { Study } \\
\text { period }\end{array}$ & Participants & $\begin{array}{l}\text { Outcomes } \\
\text { measured }\end{array}$ & Influenza vaccine protection \\
\hline \multicolumn{5}{|c|}{ Studies of seasonal IIV during pregnancy } \\
\hline Hulka [76] & $1962-1963$ & $\begin{array}{l}544 \text { pregnant women } \\
-363 \text { immunized } \\
-181 \text { nonimmunized } \\
176 \text { nonpregnant women } \\
-138 \text { immunized } \\
-38 \text { nonimmunized }\end{array}$ & $\begin{array}{l}\text { Incidence of } \\
\text { influenza-like } \\
\text { illness (ILI) }\end{array}$ & $\begin{array}{l}\text { Nonsignificant reduction in } \\
\text { incidence of ILI ( } 20 \% \text { versus } 11 \% \text { ) }\end{array}$ \\
\hline $\begin{array}{l}\text { Black et al. } \\
\text { [81] }\end{array}$ & 1997-2002 & $\begin{array}{l}49,585 \text { pregnant women } \\
-3707 \text { immunized } \\
-45,878 \text { nonimmunized }\end{array}$ & $\begin{array}{l}\text { Medical visit for } \\
\text { respiratory } \\
\text { symptoms }\end{array}$ & $\begin{array}{l}\text { No difference in medical visits } \\
(p=0.088) \\
\text { Adjusted hazard ratio }=1.151 \\
(\mathrm{CI}, 0.979-1.352) \\
\text { Clinical effectiveness: }-15 \% \\
\text { Excluding medical visits for asthma, } \\
\text { no difference }(p=0.988) \\
\text { Adjusted hazard ratio }=1.001 \\
(\mathrm{CI}, 0.838-1.196) \\
\text { Clinical effectiveness: } 0 \%\end{array}$ \\
\hline $\begin{array}{l}\text { Munoz et al. } \\
\text { [117] }\end{array}$ & 1998-2003 & $\begin{array}{l}\text { Pregnant women } \\
-252 \text { immunized } \\
-826 \text { nonimmunized }\end{array}$ & $\begin{array}{l}\text { Medically } \\
\text { attended acute } \\
\text { respiratory illness } \\
\text { (ARI) }\end{array}$ & $\begin{array}{l}\text { Nonsignificant trend toward lower } \\
\text { incidence of ARI ( } 22.6 \% \text { versus } 18.9 \% \text {; } \\
p=0.24) \\
\text { Clinical effectiveness: }-20 \% \\
(\mathrm{CI},-59.5 \text { to } 9 \% \text { ) any time during } \\
\text { pregnancy }\end{array}$ \\
\hline
\end{tabular}




\begin{tabular}{|c|c|c|c|c|}
\hline Study & $\begin{array}{l}\text { Study } \\
\text { period }\end{array}$ & Participants & $\begin{array}{l}\text { Outcomes } \\
\text { measured }\end{array}$ & Influenza vaccine protection \\
\hline \multirow[b]{2}{*}{$\begin{array}{l}\text { Zaman et al. } \\
\text { [79] }\end{array}$} & \multirow[b]{2}{*}{ 2004-2005 } & & \multirow[b]{2}{*}{$\begin{array}{l}\text { Respiratory } \\
\text { illness with fever }\end{array}$} & $\begin{array}{l}39 \%(\mathrm{CI},-56 \text { to } 76 \%) \text { during peak of } \\
\text { influenza season }\end{array}$ \\
\hline & & $\begin{array}{l}340 \text { pregnant women } \\
-172 \text { immunized with TIV } \\
-168 \text { immunized with } \\
\text { pneumococcal vaccine }\end{array}$ & & $\begin{array}{l}\text { Significant reduction of respiratory } \\
\text { illness with any fever: } \\
\text { Risk difference: }-14.2 \\
\text { (CI, }-25.5 \text { to } 2.9 \text { ) } \\
\text { Clinical effectiveness: } 35.8 \% \\
\text { (CI, 3.7-57.2\%) } \\
\text { Reduction in respiratory } \\
\text { disease with fever over } 38^{\circ} \mathrm{C} \text { : } \\
\text { Risk difference: }-7.3 \% \\
\text { (CI, }-14.5 \text { to } 0.1 \% \text { ) } \\
\text { Clinical effectiveness: } 43.1 \% \\
\text { (CI, }-9.0 \text { to } 70.3 \% \text { ) }\end{array}$ \\
\hline $\begin{array}{l}\text { Madhi et al. } \\
\text { [83] }\end{array}$ & 2011-2012 & $\begin{array}{l}2116 \text { pregnant women } \\
-1062 \text { immunized with IIV3 } \\
\text {-1054 received placebo }\end{array}$ & $\begin{array}{l}\text { RT-PCR- } \\
\text { confirmed } \\
\text { influenza }\end{array}$ & $\begin{array}{l}\text { Clinical effectiveness: } 50.4 \% \\
\text { (CI, } 14.5-71.2 \%)\end{array}$ \\
\hline $\begin{array}{l}\text { Thompson } \\
\text { et al. [84] }\end{array}$ & 2010-2012 & $\begin{array}{l}\text { Pregnant women } \\
\text {-100 with confirmed } \\
\text { influenza } \\
\text {-192 with ARI negative for } \\
\text { influenza } \\
\text {-200 control negative for } \\
\text { influenza }\end{array}$ & $\begin{array}{l}\text { RT-PCR- } \\
\text { confirmed } \\
\text { influenza }\end{array}$ & $\begin{array}{l}\text { Clinical effectiveness: } 44 \% \\
\text { (CI, 5-67\%) compared to influenza- } \\
\text { negative controls } 53 \% \\
\text { (CI, } 24-72 \%) \text { compared to } \\
\text { ARI-negative controls }\end{array}$ \\
\hline Studies of $\mathbf{P H}$ & N1 vaccine $d$ & uring pregnancy & & \\
\hline $\begin{array}{l}\text { Richards et al. } \\
\text { [101] }\end{array}$ & 2009-2010 & $\begin{array}{l}1125 \text { vaccinated } \\
1581 \text { non-vaccinated } \\
\text { (unadjuvanted vaccine) }\end{array}$ & $\begin{array}{l}\text { RT-PCR or } \\
\text { medical visit durin } \\
\text { pregnancy with } \\
\text { influenza-related } \\
\text { ICD-9 diagnosis } \\
\text { code }\end{array}$ & $\begin{array}{l}\text { Clinical effectiveness: } 61.5 \% \\
\mathrm{~g}(\mathrm{CI}, 15.5-82.5 \%)\end{array}$ \\
\hline $\begin{array}{l}\text { Haberg et al. } \\
{[53]}\end{array}$ & 2009-2010 & $\begin{array}{l}\text { 117,347 pregnant women } \\
\text { (adjuvanted vaccine) }\end{array}$ & & $\begin{array}{l}\text { Clinical effectiveness: } 70 \% \text { (AHR, } 0.30 \text {; } \\
(\mathrm{CI}), 0.25-0.34)\end{array}$ \\
\hline
\end{tabular}

Table 1. Clinical effectiveness of IIV and A(H1N1)pdm09 influenza vaccine during pregnancy.

The authors of this study speculate that while the receipt of an influenza vaccine may not prevent infection, it is likely to reduce the severity of the disease. However, they provided no data on clinical severity or evidence of such an association with vaccination status. Since there was no confirmation of influenza infection in most patients with ARI, it is impossible to confirm 
whether clinical symptoms were associated with influenza infection or with other respiratory viruses.

In 2008, Zaman et al. published the first randomized, double-blind, controlled clinical trial (RCT) of influenza vaccine in pregnant women. In this study, 340 pregnant women were randomized to receive either trivalent influenza vaccine (IIV3) or pneumococcal polysaccharide vaccine during the third trimester of pregnancy. This study was part of The Mother's Gift project, a randomized trial with the primary goal of assessing the safety and immunogenicity of pneumococcal vaccines. Therefore, the control arm consisted of mothers who received the pneumococcal vaccine, providing a control for an active, non-influenza vaccine. The authors measured nonspecific respiratory illness with fever and found that vaccinated women were significantly less likely to have respiratory illness, reporting a clinical effectiveness of $35.8 \%$ (CI, 3.7-57.2\%) for respiratory illness with any fever and $43.1 \%$ for fever over $38^{\circ} \mathrm{C}(\mathrm{CI},-9.0$ to $70.3 \%$ ) [79].

All of these studies share the common weakness that they use clinical symptoms, and not laboratory-confirmed influenza, as the primary outcome. Influenza vaccines are specifically targeted to influenza viruses. Many other respiratory pathogens can cause symptoms similar to influenza, but influenza vaccines are not designed to prevent other causes of influenza-like illness. Hence, clinical symptoms without laboratory confirmation are nonspecific outcomes. Interpretation and quantification of true vaccine effectiveness using only clinical outcomes are problematic, potentially leading to inaccurate estimates of effectiveness. For this reason, laboratory confirmation, either by reverse transcription polymerase chain reaction (RT-PCR) or viral culture, remains the best diagnostic tool for confirming influenza and evaluating vaccine efficacy (VE) and effectiveness.

In 2014, two studies began to address this deficiency in the literature. The research teams estimated influenza vaccine effectiveness in preventing illness among pregnant women using laboratory-confirmed (RT-PCR) influenza as the primary outcome.

Madhi et al. examined maternal and fetal outcomes in 2116 HIV-negative South African women during the 2011-2012 influenza season. 1062 women who received IIV3 were compared to women who received a placebo. Overall vaccine effectiveness at preventing laboratoryconfirmed (RT-PCR) influenza in this population was $50.4 \%$ (CI, 14.5-71.2) [83].

Using a large health plan database, the Pregnancy and Influenza Project evaluated seasonal vaccine efficacy during the 2010-2011 and 2011-2012 influenza seasons. The authors compared the proportion of vaccinated women among 100 RT-PCR-confirmed influenza cases with the proportion vaccinated among 192 women with ARI who tested negative for influenza, and 200 controls matched by season, site, and trimester [84]. The adjusted vaccine efficacy against influenza was of $44 \%$ (CI, 5-67\%) using the influenza-negative controls and 53\% (CI, 24-72\%) for the ARI-negative controls [84].

The $2009 \mathrm{~A}(\mathrm{H} 1 \mathrm{N1})$ pandemic provided an opportunity to improve understanding of influenza vaccination during pregnancy. The pandemic allowed an evaluation of the effectiveness of maternal vaccination during an influenza season in which there was a high rate of viral circulation, as well as a close match between the vaccine strain and the circulating viral strain. 
Pregnant women were prioritized to receive the vaccine and were strongly advised to be vaccinated [85], resulting in higher than usual vaccination rates [86].

Since the 2009 pandemic, a number of studies have examined monovalent pandemic A(H1N1) vaccination of pregnant women. Synthesizing evidence from this new and expanding database should increase our understanding of maternal influenza vaccination. While most of these studies measured either seroconversion and hemagglutinin inhibition (HAI) titers [87-92] or safety and/or birth outcomes [93-100], two studies specifically examined clinical efficacy of pandemic $\mathrm{A}(\mathrm{H} 1 \mathrm{~N} 1)$ vaccine during pregnancy.

In a retrospective cohort study, Richards et al. evaluated influenza infection in 1125 vaccinated and 1581 non-vaccinated women. In this study, influenza infection was defined as testing positive for influenza by RT-PCR or having a medical visit during pregnancy with influenzarelated ICD-9 diagnosis code during the period of 2009 influenza A(H1N1) virus circulation [101]. The researchers reported a vaccine efficacy (VE) of 61.5\% (CI, 15.5-82.5\%) for 2009 H1N1 influenza vaccine against diagnosed 2009 influenza A(H1N1) infection during the study period among all mothers in the study cohort [101].

A separate population-based study of 117,347 pregnant women in Norway estimated that vaccination during the second or third trimester of pregnancy resulted in a $70 \%$ reduction in influenza diagnosis following vaccination with adjuvanted $\mathrm{A}(\mathrm{H} 1 \mathrm{~N} 1)$ vaccine (adjusted hazard ratio, 0.30; CI, 0.25-0.34) [53].

While there is significant heterogeneity among these eight clinical studies, presenting wideranging estimates of vaccine effectiveness in pregnant women (from -15 to $70 \%$ ), the evidence of effectiveness data based on laboratory-confirmed influenza is mounting and compelling. The cumulative evidence to date provides three studies showing significant clinical effectiveness during seasonal influenza years, $35.8 \%$ against respiratory disease in a RCT [79], 50.4\% protection against laboratory-confirmed influenza in a RCT [83], and one large data-base study documenting VE of 44-53\% [84]. Two studies of vaccine effectiveness during the 2009 A(H1N1) pandemic estimated VE of $61.5 \%$ (unadjuvanted) and $70 \%$ (adjuvanted), suggesting that vaccination during a pandemic season may offer more benefit than during non-pandemic years.

These more recent estimates using laboratory-confirmed endpoints are well within the reported vaccine effectiveness for healthy, nonpregnant adults. When combined with the welldocumented observation that the antibody response to influenza vaccine in pregnant women is similar to that of nonpregnant women, all current evidence suggests that efficacy of influenza vaccines in pregnant women is similar to the nonpregnant population.

\subsection{Maternal vaccination to protect young infants}

An important secondary benefit of maternal vaccination appears to be protection of infants from influenza infection during the first months of life, providing an important two-for-one benefit since no influenza vaccine is licensed or recommended for infants younger than 6 months of age. 
Maternal vaccination has potential to protect newborns due to the transfer of maternal immunity. Transplacental transfer of antibodies occurs throughout pregnancy, with highest levels during the last $4-6$ weeks of gestation $[102,103]$. Antibodies (specifically IgG) cross the placenta from mother to fetus during the final weeks of pregnancy, while infants acquire additional immune protection during breastfeeding, when the main class of immunoglobulin transferred in breast milk is IgA [104].

Several studies have demonstrated transplacentally acquired antibodies after natural influenza infection in the mother. One study examined the cord sera of 26 infants who had cultureconfirmed influenza when younger than 4 months of age. The authors found a direct correlation between the gestational age at the time of infection and the level of antibody in the cord serum $(p=0.002)$, suggesting a protective effect of transplacentally acquired antibody [105].

During the 1979 influenza epidemic, infants of mothers with serum antibody to influenza (seropositive) were compared to infants of mothers who were seronegative [106]. The infants of seropositive mothers had higher specific serum antibody (IgG) titers against the HA influenza protein than did infants of seronegative mothers. Good correlation was found between maternal antibody titers and titers in infants (correlation, 0.81). No such correlation was found for non-immune mothers and their infants (correlation, 0.24) [106]. However, this study showed no difference in incidence of influenza infection, although infants of immune mothers showed delayed onset of symptoms and shorter duration of illness, suggesting that passive maternal immunization may delay onset and severity.

\subsubsection{Serological studies}

When evaluating vaccination response to influenza, a serum antibody titer of $\geq 1: 40$ against the HA protein is considered to be clinically relevant, resulting in a $50 \%$ decrease in symptomatic infection and, therefore, serving as a correlate of protective immunity [107]. Recent analysis of published data indicates an even higher level of clinical protection, estimating that $70 \%$ of participants are protected at a titer of 1:40, with protection increasing gradually with higher titers [108].

In the absence of a widely accepted immune correlate of protection for influenza, the analysis of hemagglutinin inhibition (HAI) seroprotection rates is generally considered a useful indicator of protection in vaccinated persons. There are challenges associated with using this antibody titer as a correlate of protection in infants, however, particularly since this correlate was determined in healthy adults [41, 107]. In any event, the US Food and Drug Administration (FDA) uses this HAI antibody titer in evaluation of influenza vaccines, making the HAI antibody titer the standard used by most investigators [40], including those examining vaccine protection in neonates.

In a study examining transplacental transfer of antibody in response to vaccination, Englund et al. studied women during the last trimester of pregnancy who were vaccinated with IIV3 (A/Sichuan/H3N2, A/Taiwan/H1N1, B/Victoria). Maternal immunization resulted in the transfer of influenza-specific IgG to the infants. When measured at the time of delivery, the levels of antibody transferred were high, with between 87 and $99 \%$ of antibody detectable in 
the mother also detectable in the infant [78]. The antibody titers to at least two of the three influenza antigens (influenza H3N2 and influenza B) remained significantly elevated up to 2 months of age [78].

Sumaya and Gibbs vaccinated pregnant women and reported a similar correlation, finding that cord blood HAI antibody in infants correlated with titers of vaccine-stimulated HAI antibody in mothers, with HAI antibody detected in $54 \%$ of newborn serum and $73 \%$ of maternal serum [75]. This study did not examine infant influenza infection as an outcome, so the study was unable to correlate serum antibody levels with clinical outcome.

While these previous studies demonstrated that maternal antibody appears to be transferred to infants following both natural infection and vaccination, neither study discussed whether the level maternal antibody was high enough to confer protective immunity to the infant [41, 107]. Using HAI titer as a correlate of immunity, Steinhoff et al. did conduct an RCT of maternal influenza vaccine. Serum samples were obtained from 311 mothers before vaccination and at delivery and from 292 infants at birth at 10 weeks and 20-26 weeks later [109]. The proportion of mothers with a protective antibody titer $(\mathrm{HAI} \geq 1: 40)$ at the time of delivery was $88 \%$ for $\mathrm{A} /$ New Caledonia (H1N1), 98\% for A/Fujian (H3N2), and 45\% for B/Hong Kong. Similar proportions of infants had protective antibody titers at birth [109].

Yamaguchi et al. also examined the immune responses to influenza vaccination during pregnancy by measuring the effect of influenza vaccination (IIV3) in pregnancy, including maintenance of the specific antibody response, and the efficiency of transplacental transfer of the antibody to the fetus. The study included 125 pregnant women, 71 in their second trimester and 54 during the third trimester of pregnancy. The authors reported that vaccination at any time during pregnancy yielded protective levels of antibody in both maternal and fetal blood [110].

In a prospective study examining the immunogenicity and transplacental transmission of antibodies in pregnant women in Asia, Lin et al. enrolled 46 pregnant women who received a single dose of IIV3. Twenty-eight days after vaccination, the seroprotection rate in vaccinated women against $\mathrm{H} 1 \mathrm{~N} 1, \mathrm{H} 3 \mathrm{~N} 2$, and influenza B was 91.3, 84.8, and 56.5\%, respectively [111].

Several additional studies have demonstrated transplacental antibody transfer following maternal vaccination with pandemic H1N1 vaccine. Three studies evaluated adjuvanted $\mathrm{A}(\mathrm{H} 1 \mathrm{~N} 1)$ vaccines, and two studied nonadjuvanted $\mathrm{A}(\mathrm{H} 1 \mathrm{~N} 1)$ vaccine. All five of the studies documented protective levels of antibody in significant percent of infants (79-95\%).

Zuccotti et al. followed 69 mother-infant pairs. The women were vaccinated during their third trimester of pregnancy with MF59-adjuvanted influenza A(H1N1) vaccine. All of the mothers had HAI antibody titers at or above 1:40 at the time of delivery and throughout the 5 months of follow-up. Ninety-five percent of the infants had HAI antibody titers at or about 1:40 at both birth and 2 months of age. By 5 months of age, the proportion of infants with titers of 1:40 dropped to $81.2 \%$ [89], suggesting that passively acquired antibody at levels thought to be protective is transferred and persists for at least 5 months.

In a separate study performed at three sites in the UK, researchers followed infants born to mothers who were vaccinated with AS03-adjuvanted $\mathrm{H} 1 \mathrm{~N} 1$ vaccine during the second or third 
trimester of pregnancy. This study found that $79 \%$ of the infants of vaccinated mothers had serum antibody titers at or higher than 1:40 compared to a background immunity in 19\% of infants of unvaccinated women $(p=0.001)$ [112].

Helmig et al. evaluated the serological response of a cohort of women immunized with adjuvanted $\mathrm{A}(\mathrm{H} 1 \mathrm{~N} 1)$ vaccine or by natural infection with $\mathrm{A}(\mathrm{H} 1 \mathrm{~N} 1) \mathrm{pdm} 09$. The authors detected protective antibody levels (>1:40) in a significant number 17/19 (89.5\%) of newborns born to vaccinated mothers $(p=0.001)$ [113]. Notably, while natural influenza infection conferred protective antibody levels in mothers, it did not contribute to protective levels in their infants; only $15.8 \%$ of infants born to women who had natural influenza infection during pregnancy developed protective levels of antibody at birth.

In a study of nonadjuvanted $\mathrm{A}(\mathrm{H} 1 \mathrm{~N} 1)$ vaccine, Tsatsaris et al. measured $\mathrm{Ab}$ titers in cord blood of 88 infants born to women vaccinated with a single dose of monovalent $A(H 1 N 1)$ vaccine. The researchers reported 95\% (CI, 89-99\%) of infants have protective levels of antibody (>1:40) at birth [114], and Fisher et al. also reported protective levels of Ab in cord blood of infants following maternal vaccination with 2009 monovalent A(H1N1) [115].

Taken together, these studies provide an important proof of concept for transplacentally acquired antibody, from either natural infection or vaccination of their mother, to potentially protect young infants from influenza infection and present maternal immunization as a promising strategy for reducing influenza infection in infants.

\subsubsection{Clinical studies}

Over the past 11 years, nine studies have been published evaluating the effect of maternal immunization on influenza in 97,656 infants across 15 influenza seasons. Six of these studies showed clinical protection; three studies did not (Table 2).

\begin{tabular}{|c|c|c|c|c|}
\hline Study & $\begin{array}{l}\text { Study } \\
\text { period }\end{array}$ & Participants & Outcomes measured & $\begin{array}{l}\text { Protection by maternal influenza } \\
\text { vaccine }\end{array}$ \\
\hline $\begin{array}{l}\text { Black et al. } \\
{[81]}\end{array}$ & $\begin{array}{l}1997- \\
2002\end{array}$ & 49,585 pregnant women & $\begin{array}{l}\text { Hospitalization for } \\
\text { pneumonia and } \\
\text { influenza }\end{array}$ & $\begin{array}{l}\text { No difference in risk for hospitalization } \\
(p=0.235) \\
\text { Adjusted hazard ratio: } 0.956 \text { (CI, } 0.889- \\
1.029) \\
\text { Clinical effectiveness: } 4 \% \text { (CI, }-3 \text { to } 11 \%) \\
\text { No difference in risk including otitis } \\
\text { media visit ( } p=0.506) \\
\text { Adjusted hazard ratio: } 0.938 \text { (CI, } 0.777- \\
1.132) \\
\text { Clinical effectiveness: } 6 \%(\mathrm{CI},-13 \text { to } \\
22 \%)\end{array}$ \\
\hline $\begin{array}{l}\text { Munoz et al. } \\
\text { [117] }\end{array}$ & $\begin{array}{l}1998- \\
2003\end{array}$ & $\begin{array}{l}225 \text { infants of } \\
\text { immunized mothers }\end{array}$ & Hospitalization or & No difference in hospitalization \\
\hline
\end{tabular}




\begin{tabular}{|c|c|c|c|c|}
\hline Study & $\begin{array}{l}\text { Study } \\
\text { period }\end{array}$ & Participants & Outcomes measured & $\begin{array}{l}\text { Protection by maternal influenza } \\
\text { vaccine }\end{array}$ \\
\hline & & $\begin{array}{l}826 \text { infants of } \\
\text { nonimmunized } \\
\text { mothers }\end{array}$ & $\begin{array}{l}\text { clinic visits for } \\
\text { respiratory conditions }\end{array}$ & $\begin{array}{l}\text { During first month, infants of immunized } \\
\text { moms had more clinic visits for } \\
\text { bronchitis }(p=0.04) \text { and fewer for } \\
\text { respiratory distress }(p=0.04) \\
\text { No other differences }\end{array}$ \\
\hline $\begin{array}{l}\text { France et al. } \\
{[116]}\end{array}$ & $\begin{array}{l}1995- \\
2001\end{array}$ & $\begin{array}{l}3160 \text { infants of } \\
\text { immunized mothers } \\
37,969 \text { infants of } \\
\text { nonimmunized women }\end{array}$ & $\begin{array}{l}\text { Medically attended } \\
\text { acute respiratory illness } \\
(\mathrm{ARI})\end{array}$ & $\begin{array}{l}\text { No reduction in clinic visit rates } \\
\text { Incident rate ratio: } 0.96(\mathrm{CI}, 0.86-1.07)\end{array}$ \\
\hline $\begin{array}{l}\text { Zaman et al. } \\
\text { [79] }\end{array}$ & $\begin{array}{l}2004- \\
2005\end{array}$ & $\begin{array}{l}316 \text { infant-mother pairs } \\
\text { followed for } 24 \text { weeks }\end{array}$ & $\begin{array}{l}\text { Clinic visits for } \\
\text { respiratory illness } \\
\text { Laboratory-confirmed } \\
\text { influenza before } 24 \\
\text { weeks of age } \\
\text { (confirmation by rapid } \\
\text { test) }\end{array}$ & $\begin{array}{l}63 \% \text { effective at preventing laboratory- } \\
\text { confirmed influenza in infants up to } 6 \\
\text { months old (CI, } 5-85 \%) \\
29 \% \text { effective in preventing febrile illness } \\
(\mathrm{CI}, 6.9-45.7 \%) \\
42 \% \text { effective in preventing clinic visit } \\
(\mathrm{CI}, 18.2-58.8 \%)\end{array}$ \\
\hline $\begin{array}{l}\text { Benowitz et } \\
\text { al. [118] }\end{array}$ & $\begin{array}{l}2000- \\
2009\end{array}$ & $\begin{array}{l}\text { Infants less than } 12 \\
\text { months old } \\
-220 \text { cases } \\
-430 \text { matched controls }\end{array}$ & $\begin{array}{l}\text { Laboratory-confirmed } \\
\text { influenza (confirmation } \\
\text { by direct fluorescent } \\
\text { antibody (DFA) test) }\end{array}$ & $\begin{array}{l}91.5 \% \text { effective at preventing } \\
\text { hospitalization of infants less than } 6 \\
\text { months of age ( } p=0.001 ; \mathrm{CI}, 61.7-98.1 \% \text { ) } \\
\text { No significant effect on infants older than } \\
6 \text { months }\end{array}$ \\
\hline $\begin{array}{l}\text { Eick et al. } \\
{[120]}\end{array}$ & $\begin{array}{l}2002- \\
2005\end{array}$ & $\begin{array}{l}1169 \text { infant-mother } \\
\text { pairs }\end{array}$ & $\begin{array}{l}\text { Laboratory-confirmed } \\
\text { influenza (confirmation } \\
\text { by viral culture, } \\
\text { fourfold rise in HAI } \\
\text { antibody in cord serum } \\
\text { or rapid test) }\end{array}$ & $\begin{array}{l}\text { Laboratory-confirmed influenza } \\
\text { decreased among infants born to } \\
\text { vaccinated women compared to controls } \\
\text { Risk ratio } 0.59 \text { (CI, } 0.37-0.93) \\
\text { Clinical effectiveness: } 41 \% \\
\text { Hospitalization } \\
\text { Risk ratio } 0.61 \text { (CI, } 0.45-0.84) \\
\text { Clinical effectiveness: } 39 \%\end{array}$ \\
\hline $\begin{array}{l}\text { Poehling et } \\
\text { al. [126] }\end{array}$ & $\begin{array}{l}2002- \\
2009\end{array}$ & $\begin{array}{l}\text { Infants less than } \\
6 \text { months old } \\
\text { hospitalized with } \\
\text { fever or } \\
\text { respiratory symptoms } \\
-151 \text { cases } \\
-1359 \text { controls }\end{array}$ & $\begin{array}{l}\text { Laboratory-confirmed } \\
\text { influenza (confirmation } \\
\text { by viral culture or } \\
\text { PCR) }\end{array}$ & $\begin{array}{l}\text { Hospitalized infants whose mothers were } \\
\text { immunized were } 45-48 \% \text { less likely to } \\
\text { have laboratory-confirmed influenza } \\
\text { Adjusted odds ratio (OR) } 0.52 \\
\text { (CI, } 0.30-0.91)\end{array}$ \\
\hline $\begin{array}{l}\text { Sugimura et } \\
\text { al. [127] }\end{array}$ & $\begin{array}{l}2010- \\
2011\end{array}$ & $\begin{array}{l}200 \text { infants from birth } \\
\text { to } 6 \text { months of age } \\
-106 \text { infants of } \\
\text { vaccinated mothers }\end{array}$ & $\begin{array}{l}\text { Laboratory-confirmed } \\
\text { influenza (confirmation } \\
\text { by rapid test) }\end{array}$ & $\begin{array}{l}\text { Significant difference in incidence of } \\
\text { influenza between infants of vaccinated } \\
\text { versus unvaccinated mothers } \\
(p=0.019)\end{array}$ \\
\hline
\end{tabular}




\begin{tabular}{|c|c|c|c|c|}
\hline$\overline{\text { Study }}$ & $\begin{array}{l}\text { Study } \\
\text { period }\end{array}$ & Participants & Outcomes measured & $\begin{array}{l}\text { Protection by maternal influenza } \\
\text { vaccine }\end{array}$ \\
\hline & & $\begin{array}{l}-90 \text { infants of } \\
\text { unvaccinated mothers }\end{array}$ & & \\
\hline $\begin{array}{l}\text { Madhi et al. } \\
\text { [83] }\end{array}$ & $\begin{array}{l}2011- \\
2012\end{array}$ & $\begin{array}{l}2046 \text { infants } \\
\text {-1026 infants of } \\
\text { vaccinated mothers } \\
\text { - } 1023 \text { infants of } \\
\text { placebo mothers }\end{array}$ & $\begin{array}{l}\text { Laboratory-confirmed } \\
\text { influenza RT-PCR }\end{array}$ & $\begin{array}{l}\text { Vaccine efficacy of } 48.8 \% \text { (CI, } 11.6- \\
70.4 \%)\end{array}$ \\
\hline
\end{tabular}

Table 2. Clinical effectiveness of maternal vaccination for protection of infants.

\subsubsection{Studies finding no protective effect}

In a retrospective cohort study of 48,639 infants, Black et al. found that infants born to vaccinated women had the same risk of hospitalization for influenza or pneumonia as infants of unvaccinated women (CI, 0.889-1.029). They also reported that maternal vaccination was not a significant determinant of risk for ILI or otitis media [81].

France et al. followed 3160 infants of immunized mothers and 37,969 infants of nonimmunized mothers from 1995-2001 and during four specific seasonal periods: peak influenza, respiratory syncytial virus predominant, periseasonal, and summer weeks [116]. They found no difference in medically attended ARI (incident rate ratio for peak influenza season 0.96, CI, 0.86-1.07), concluding "maternal influenza vaccination did not reduce visit rates during any of the four time periods and did not delay the onset of first respiratory illness" [116].

In a study that included an examination of data over five influenza seasons, Munoz et al. reported similar results, finding no difference in hospitalizations for respiratory illness during the peak of influenza season between infants of vaccinated mothers versus infants of nonvaccinated mothers [117].

\subsubsection{Studies finding clinical protection}

While the three earlier studies above found no benefit to infants from maternal vaccination, a more recent matched case-control study of infants less than 12 months old admitted to hospitals for seasonal influenza between 2000 and 2009 reported maternal vaccination to be $91.5 \%$ effective (CI, 61.7-98.1\%, $p=0.001$ ) in preventing hospitalization of infants younger than 6 months of age [118]. Maternal vaccination was not effective in preventing hospitalization for infants older than 6 months (-41.4\% (CI, 0.153-0.918)). In this study, influenza cases from 2007 to 2009 were confirmed by direct fluorescent antibody (DFA) test, which was reported to be $96.2 \%$ sensitive and $99 \%$ specific for influenza [119]. A limitation to this study is that results from nine influenza seasons were combined, with no information regarding the strain match of vaccine to circulating strain for each influenza season. The researchers did not type the strain of influenza in infected infants, stating that they "did not have adequate power to assess the 
vaccine's effectiveness by influenza season... and did not type strains to determine whether influenza infections were caused by strains included in the vaccine" [118].

Eick et al. conducted a study in the White Mountain and Navajo reservations over three influenza seasons, November 2002 to September of 2005. In this prospective cohort study, the effect of influenza vaccine during pregnancy on influenza infection in infants was compared between infants of vaccinated women and those born to non-vaccinated women. The authors analyzed 83 confirmed influenza cases. Of these cases, seven ( $86 \%$ ) were confirmed by serology, ten $(12 \%)$ by viral culture, and two $(2 \%)$ by rapid influenza testing. Using these three measures of influenza infection, the authors reported a $41 \%$ reduction in the risk of laboratory-confirmed influenza for infants born to vaccinated women (RR 0.59, CI, 0.37-0.93) and a 39\% reduction in the risk of ILI hospitalization (RR 0.61, CI, 0.45-0.84) [120].

The authors of this study pooled the results from three different assay methods, each with different sensitivities, to document influenza infection. Pooling assays with differing diagnostics represents a limitation of this study. Likewise, the use of serology to document influenza in most $(86 \%)$ of cases represents a weakness of this study. The authors describe serological documentation of influenza infection as a fourfold or greater increase in HAI antibody in serum collected at 2-3 or 6 months compared with previous serum specimen [120]. Significant limitations have been reported regarding the use of serology in diagnosing influenza in adult patients that have been vaccinated with inactivated vaccines [121-123]. Using serology to document influenza infection in young infants presents additional complications.

Infants under 6 months of age have immature, immunologically inexperienced immune systems. Since their ability to produce antibody in response to infection is often delayed or completely absent, many of their serum antibodies are maternally derived. More than 50 years ago, the use of serology for diagnosis of influenza in infancy was questioned. During an influenza outbreak in Glasgow in 1953, fourfold increases in antibody were found in only $20 \%$ of infants admitted to pediatric pneumonia wards (as compared to $30 \%$ of adult cases) [124]. In two different outbreaks, antibody production was absent or considerably delayed in infected children under 18 months of age, even when virus could be isolated [125]. These observations illustrate the difficulties inherent in using serology to document influenza infection in young infants.

In the only randomized, blinded clinical study to assess infant protection, Zaman et al. reported a vaccine effectiveness of $63 \%(C I, 5-85 \%)$ against laboratory-confirmed influenza in infants up to 6 months of age [79]. Influenza was confirmed by rapid test (Z Stat Flu), which was reported to have a specificity of $80-90 \%$ and a sensitivity of $70-72 \%$ for type A and type B influenza. When respiratory illness and fever were used as measure of disease, the reported effectiveness was $29 \%$ (CI, 7-46\%) [79].

A recent study sought to determine whether maternal vaccination during pregnancy was associated with a reduced risk or laboratory-confirmed influenza hospitalizations in 1510 infants over seven consecutive influenza seasons (2002-2003 through 2008-2009) and across three diverse geographic regions of the United States [126]. Of the 1510 infants hospitalized with fever or respiratory symptoms, $151(10 \%)$ had laboratory-confirmed (by viral culture or 
RT-PCR) influenza. The proportion of infants who were influenza positive varied significantly across influenza seasons, from 3\% in 2006-2007 to 15\% in 2003-2004. The percentage of women who were vaccinated also varied by season, from $10 \%$ in $2003-2004$ to $38 \%$ in $2008-2009$.

Among influenza-positive infants during all study years, $12 \%$ of their mothers reported being vaccinated during pregnancy, while $20 \%$ of mothers of influenza-negative infants reported receiving a vaccination [126], yielding an adjusted odds ratio of 0.52 (CI, 0.30-0.91) and suggesting that infants whose mothers received influenza vaccines during pregnancy were $48 \%$ less likely to have laboratory-confirmed influenza than infants of unvaccinated women [126].

In a randomized, placebo-controlled trial of influenza vaccination in South Africa, Madhi et al. followed 1026 infants born to women who received IIV3 and 1023 infants born to placebo recipients. The attack rate of influenza was lower among infants of vaccinated mothers $(1.9 \%)$ than among those whose mothers received placebo vaccine $(3.6 \%)$, yielding a vaccine effectiveness of $57.5 \%$ (CI, 7.6-70.4) in this population [83].

In a prospective study, Sugimura et al. assessed the incidence of fever and laboratory-confirmed influenza in newborns whose mothers were vaccinated during pregnancy with IIV3. Two hundred infants were followed from birth to 6 months of age. Fever was noted in $36(34 \%)$ of the infants in the vaccinated group and $47(52.2 \%)$ of infants born to unvaccinated mothers $(p<0.007)$. The incidence of influenza as diagnosed by rapid test was $0(0 \%)$ and $5(5.6 \%)$, respectively, $(p=0.019)$ [127].

The reviewed studies assessed hospitalization, clinic visits, ARI, or laboratory-confirmed influenza as primary outcomes. Rationale for influenza vaccination often includes additional secondary outcomes such as reduction of absenteeism for household contacts, secondary infections, acute otitis media, or community transmission of influenza. While these outcomes are important in measuring the broad impact of influenza, they do not provide accurate assessment of vaccine efficacy or effectiveness. Such an assessment is essential for evidencebased, reasoned development of public health policy and decision-making about influenza prevention.

In summary, the evidence for newborn protection through maternal vaccination is encouraging, but several studies exhibit methodological limitations. The results of studies measuring rates of ARI, clinic visit, or hospitalization range from no vaccine effect up to $42 \%$ effectiveness $[81,116,117]$. The six studies that used some form of laboratory-confirmed influenza (rapid tests, viral culture, or PCR) as the primary outcome are more encouraging, reporting vaccination effectiveness ranging from 41 to $91.5 \%[79,83,118,120,126,127]$.

While outcomes and study designs differ, in general the data to date suggest that maternal vaccination has the potential to decrease influenza illness in newborns. As such, maternal immunization during pregnancy should continue to be recommended and encouraged for all women. 


\section{Current challenges}

Influenza is a complex disease. For centuries it has eluded complete understanding or control. Constantly evolving and catching us by surprise, influenza is a perpetually emerging disease. The main tool for prevention of influenza is vaccination, the cornerstone for prevention of influenza disease. However, unlike many other vaccines, the effectiveness of influenza vaccines remains moderate to marginal across all populations [128], and in addition, the vaccines need to be administered every year. A universal influenza vaccine providing broad and long-lasting protection continues to be elusive.

These realities-difficult enough in the general population-are even more challenging to understand during pregnancy. Particularly complex is determining how, or if, the changing immune responses over pregnancy vis-a-vis influenza season and vaccination schedules impact vaccine effectiveness and disease outcomes in pregnant women.

A recent critique by Savitz et al. calls into question our most basic understanding of influenza infection during pregnancy, with a particular critique on the quality of the evidence for a benefit of maternal vaccination in prevention of harm from seasonal influenza [129]. Savitz et al. discuss the complications inherent in many current research practices, which serve to limit our understanding of the true picture of maternal influenza. Central to this critique is the notion that both pregnancy and influenza have temporal components; influenza typically is seasonal, with a 2-3-month period of circulation each year. But pregnancy has trimesters, each with distinct fetal developmental stages along with physiological and immunological changes in the expectant mother. To complicate this further, the risk of adverse outcomes from influenza infection is not equal across all trimesters of pregnancy. Therefore, optimizing risk and benefit of vaccination during pregnancy is complicated and likely requires reexamination of influenza risk and benefit across trimesters in association with months of influenza circulation [129].

A recent WHO review of influenza throughout pregnancy found insufficient data from comparable studies to discern which specific weeks, months, or trimesters influenza poses increased risk to pregnant women [130]. Savitz et al. assert that "As with all time dependent states, pregnancies must be followed longitudinally. There needs to be a week-by-week consideration of the pregnancy with regard to vaccination status and circulating influenza viruses" [129].

Aside from complications associated with potential differences in virus exposure across the trimesters of a pregnancy, risks posed to pregnant women also may differ according to the specific strain circulating during a given season, and, likewise, the immune response to vaccination also could differ based on strain [131].

Even when taking yearly strain differences into account, variation in immune responses across trimesters adds yet another complicating variable. It is widely accepted that the immune response to influenza vaccine in pregnant women is indistinguishable from that of nonpregnant women and that gestational age appears to have no effect on antibody response $[75,76$, $132,133]$. 
Findings from more recent studies suggest that we may need to entertain a more nuanced approach to our understanding of the maternal immune response to influenza vaccinationprecisely because immunogenicity and seroconversion may not tell the entire story.

In a 2011 study, Ohfuji et al. reported a lower seroprotective antibody response to pandemic $\mathrm{A}(\mathrm{H} 1 \mathrm{~N} 1)$ vaccine in pregnant women who had received prior seasonal influenza vaccine and suggested that the potential interference between $\mathrm{pH} 1 \mathrm{~N} 1$ and seasonal vaccination needed additional investigation [15]. Schlaudecker et al. directly compared immunogenicity of inactivated influenza vaccine in pregnant versus nonpregnant women and found that pregnancy modified antibody responses to the vaccine [134]. They demonstrated a significantly decreased postimmunization HAI geometric mean titer and a nonsignificantly decreased geometric mean ratio (fold increase) to influenza A antigens after influenza vaccine, even though overall seroconversion and seroprotection rates were comparable between the two groups of women. In a 2013 blinded randomized control study, Bischoff et al. found that the immune response to an adjuvanted pandemic $A(H 1 N 1)$ vaccine in pregnant women was decreased compared with nonpregnant women [133]. Sperling et al. examined HAI titers over pregnancy and found that timing of vaccination did not alter response, although there was a trend toward lower responses during the first trimester and six weeks postpartum [135].

A small study of 36 women during the 2012-2014 flu seasons suggests that T-follicular helper (Tfh) cell response to vaccination was highest during the first trimester of pregnancy. Tfh cells are required for the generation of high-quality antibody-producing B cells. Their expansion has been shown to be a predictor of response to influenza vaccination outside of pregnancy suggesting that immunologic changes during pregnancy may impact vaccine response. Notably, there was no significant expansion of Tfh after vaccination during either the second or third trimester [136].

In a study aimed to determine the optimal timing for vaccination within the second or third trimesters of pregnancy, Yamaguchi et al. reported that serum antibody levels in vaccinated women depended not on gestational stage but on the amount of time elapsed, since vaccination antibody titers decreased with time [110]. This observation is supported by other studies documenting that influenza-specific antibodies after vaccination are typically short lived [115].

Two separate studies of vaccine effectiveness in nonpregnant adults during the 2011-2012 influenza season also suggest that vaccine effectiveness wanes with time since vaccination $[137,138]$. In both of these studies, vaccination effectiveness waned in people who were vaccinated 93 days - around 3 months - or more before presentation of symptoms. A similar observation was made by Fisher et al. who demonstrated a significant linear decline over time in HAI titers after pH1N1 infection or vaccination $(p=0.04$ for infected and $p=0.009$ for vaccinated) [115].

Taken together, these observations support a consensus that pregnant women are capable of mounting a robust immune response to influenza vaccination during the second and third trimester of pregnancy. Experimental evidence during the first trimester is less clear, 
due in part to a limited number of studies on influenza vaccination during the first trimester.

There is increasing evidence suggesting that - regardless of initial vaccine response - the level of vaccine-mediated anti-influenza-specific antibodies decreases with time. This waning of antibody implies that women vaccinated during the first trimester of pregnancy might be less well protected as their pregnancy progresses. It is well documented that serious influenzarelated morbidity in healthy pregnant women most often occurs during the second and third trimester of pregnancy. So a reasonable goal appears to be ensuring the highest possible level of protection during the second and third trimesters. Studies on waning immunity suggest that this may be precisely opposite of what occurs in women who are vaccinated early in pregnancy; protection wanes as risk increases.

\subsection{Timing maternal vaccination for protection of neonates}

Cross-placental transfer of immunity occurs when antibodies cross the placenta via active transport, particularly in the final weeks of pregnancy. It is logical to assume that vaccineinduced maternal antibody transmitted to the fetus will provide protection to the infant during the first months of life, and several studies document increased antibody titers in infants of vaccinated mothers [120].

Comparable to studies of vaccinated mothers, researchers have demonstrated that the titers of influenza-specific antibodies in newborns, while not affected by trimester of maternal vaccination (within second or third trimester), do wane with time and are short lived [75]. Tsatsaris et al. also noted a trend toward lower cord blood antibody titer associated with longer intervals between maternal vaccination and delivery. A similar observation was made by Yamaguchi et al. who reported that transfer rate from the maternal blood to the fetal blood at time of delivery tended to be inversely correlated with duration of gestation postvaccination [110]. Some additional studies have hinted at lower cord blood titers among infants of women vaccinated in the first trimesters, but it is unclear if this is clinically significant [131].

Taken together, these studies serve to highlight the complicated nature of immunity particularly during pregnancy in response to vaccination and invite further virological and epidemiological studies to confirm and fully understand these observations and to correlate changes in antibody titer with clinical outcomes in both mothers and infants. As our understanding evolves, we may need to develop a more nuanced approach - one that takes into consideration the trimester of exposure to both circulating virus and vaccines - to optimize vaccine effectiveness during the period of highest risk of influenza disease.

The recommendation to vaccinate all pregnant women regardless of gestational age is motivated in part by operational concerns. Timing of the influenza vaccine campaigns occurs in the fall in temperate regions. Pregnancy, on the other hand, occurs throughout the year. Since pregnancy presents a period of regularly scheduled and repeat visits, a more tailored approach to influenza vaccine coverage may be appropriate in order to stack the odds in favor of the highest level of protection for both mother and infant. 


\section{Conclusions}

The impact of influenza infection on pregnant women and newborns is well documented. The increased risk for morbidity and mortality has resulted in the universal recommendation that pregnant women be vaccinated for influenza at any stage of pregnancy [65]. Evidence to date suggests that influenza vaccination during pregnancy is similarly effective as in the nonpregnant population. Pregnant women mount robust immune response that correlates with clinical efficacy. This immunity then is transferred to the fetus during gestation, providing clinical benefit to infants less than 6 months of age. And while not a component of this review, there is substantial evidence that influenza vaccines are safe during all stages of pregnancy with no evidence of risk of adverse pregnancy outcome linked to influenza vaccines $[3,65,131,139$, 140].

Gaps remain in our understanding of influenza risk over all seasons and trimesters, of maternal immunity, and of optimal timing of vaccination. To this end, in January of 2015, the Bill and Melinda Gates Foundation held a meeting of global stakeholders in the maternal influenza field. Participants identified a need for stronger evidence regarding, among other issues, the burden of disease and maternal immunization efficacy [141]. Expanding this evidence base will allow for a deeper understanding of influenza in this population and the development of more robust and efficacious public health approaches toward this disease.

\section{Author details}

Jill M. Manske

Address all correspondence to: jmmanske@stthomas.edu

University of St. Thomas, Saint Paul, MN, USA

\section{References}

[1] World Health Organization, WHO position paper on influenza vaccines. Wkly Epidemiol Record 2005; 33: 279-287)

[2] Tamma PD, Steinhoff MC, Omer SB. Influenza infection and vaccination in pregnant women. Expert Rev Respir Med 2010;4:321-8.

[3] Mak TK, Mangtani P, Leese J, Watson JM, Pfeifer D. Influenza vaccination in pregnancy: current evidence and selected national policies. Lancet Infect Dis 2008;8:44-52. 
[4] Neuzil KM, Reed GW, Mitchel EF, Simonsen L, Griffin MR. Impact of influenza on acute cardiopulmonary hospitalizations in pregnant women. Am J Epidemiol 1998;148:1094102.

[5] Schanzer DL, Langley JM, Tam TW. Influenza-attributed hospitalization rates among pregnant women in Canada 1994-2000. J Obstet Gynaecol Can 2007;29:622-9.

[6] Jamieson DJ, Theiler RN, Rasmussen SA. Emerging infections and pregnancy. Emerg Infect Dis 2006;12:1638-43.

[7] Skowronski DM, De Serres G. Is routine influenza immunization warranted in early pregnancy? Vaccine 2009;27:4754-70.

[8] Gaunt G, Ramin K. Immunological tolerance of the human fetus. Am J Perinatol 2001;18:299-312.

[9] Szekeres-Bartho J. Immunological relationship between the mother and the fetus. Int Rev Immunol 2002;21:471-95.

[10] Davies M, Browne CM. Pregnancy-associated nonspecific immunosuppression: kinetics of the generation and identification of the active factors. Am J Reprod Immunol Microbiol 1985;9:77-83.

[11] Saleeby E, Chapman J, Morse J, Bryant A. H1N1 influenza in pregnancy: cause for concern. Obstet Gynecol 2009;114:885-91.

[12] Laibl VR, Sheffield JS. Influenza and pneumonia in pregnancy. Clin Perinatol 2005;32:727-38.

[13] Griffiths PD, Ronalds CJ, Heath RB. A prospective study of influenza infections during pregnancy. J Epidemiol Community Health 1980;34:124-8.

[14] Lindsay L, Jackson LA, Savitz DA, Weber DJ, Koch GG, Kong L, et al. Community influenza activity and risk of acute influenza-like illness episodes among healthy unvaccinated pregnant and postpartum women. Am J Epidemiol 2006;163:838-48.

[15] Ohfuji S, Fukushima W, Deguchi M, Kawabata K, Yoshida H, Hatayama H, et al. Immunogenicity of a monovalent 2009 influenza A (H1N1) vaccine among pregnant women: lowered antibody response by prior seasonal vaccination. J Infect Dis 2011;203:1301-8.

[16] Dodds L, McNeil SA, Fell DB, Allen VM, Coombs A, Scott J, et al. Impact of influenza exposure on rates of hospital admissions and physician visits because of respiratory illness among pregnant women. CMAJ 2007;176:463-8.

[17] Cox S, Posner SF, McPheeters M, Jamieson DJ, Kourtis AP, Meikle S. Hospitalizations with respiratory illness among pregnant women during influenza season. Obstet Gynecol 2006;107:1315-22. 
[18] Hartert TV, Neuzil KM, Shintani AK, Mitchel EF, Jr., Snowden MS, Wood LB, et al. Maternal morbidity and perinatal outcomes among pregnant women with respiratory hospitalizations during influenza season. Am J Obstet Gynecol 2003;189:1705-12.

[19] Kort BA, Cefalo RC, Baker VV. Fatal influenza A pneumonia in pregnancy. Am J Perinatol 1986;3:179-82.

[20] Housworth J, Langmuir AD. Excess mortality from epidemic influenza, 1957-1966. Am J Epidemiol 1974;100:40-8.

[21] Callaghan WM, Chu SY, Jamieson DJ. Deaths from seasonal influenza among pregnant women in the United States, 1998-2005. Obstet Gynecol 2010;115:919-23.

[22] Nuzum JW, Pilot I, Stangl FH, Bonar BE. 1918 pandemic influenza and pneumonia in a large civil hospital. IMJ Illinois Med J 1976;150:612-6.

[23] Freeman DW, Barno A. Deaths from Asian influenza associated with pregnancy. Am J Obstet Gynecol 1959;78:1172-5.

[24] Greenberg M, Jacobziner H, Pakter J, Weisl BA. Maternal mortality in the epidemic of Asian influenza, New York City, 1957. Am J Obstet Gynecol 1958;76:897-902.

[25] Harris JW. Influenza occurring in pregnant women: a statistical study of thirteen hundred and fifty cases. J Am Med Assoc 1919;72:978-80.

[26] Woolston, W.J., Conley D.O. Epidemic pneumonia (Spanish influenza) in pregnancy: effect in one hundred and one cases. J Am Med Assoc 1918;71:1898-9.

[27] CDC. Novel influenza A (H1N1) virus infection in three pregnant women-United States. MMWR Morb Mortal Wkly Rep 2009;58:497-500.

[28] Panda B, Panda A, Riley LE. Selected viral infections in pregnancy. Obstet Gynecol Clin North Am 2010;37:321-31.

[29] CDC. Hospitalized patients with novel influenza A (H1N1) virus infection-California. MMWR Morb Mortal Wkly Rep 2009;58:536-41.

[30] Jamieson DJ, Honein MA, Rasmussen SA, Williams JL, Swerdlow DL, Biggerstaff MS, et al. H1N1 2009 influenza virus infection during pregnancy in the USA. Lancet 2009;374:451-8.

[31] Louie JK, Acosta M, Jamieson DJ, Honein MA. Severe 2009 H1N1 influenza in pregnant and postpartum women in California. N Engl J Med 2010;362:2735.

[32] Mosby LG, Rasmussen SA, Jamieson DJ. 2009 Pandemic influenza A (H1N1) in pregnancy: a systematic review of the literature. Am J Obstet Gynecol 2011. 
[33] Callaghan WM, Creanga AA, Jamieson DJ. Pregnancy-related mortality resulting from influenza in the United States during the 2009-2010 pandemic. Obstet Gynecol 2015;126:486-90.

[34] Siston AM, Rasmussen SA, Honein MA, Fry AM, Seib K, Callaghan WM, et al. Pandemic 2009 influenza A(H1N1) virus illness among pregnant women in the United States. JAMA 2010;303:1517-25.

[35] Yates L, Pierce M, Stephens S, Mill AC, Spark P, Kurinczuk JJ, et al. Influenza A/H1N1v in pregnancy: an investigation of the characteristics and management of affected women and the relationship to pregnancy outcomes for mother and infant. Health Technol Assess 2010;14:109-82.

[36] Gerardin P, El Amrani R, Cyrille B, Gabriele M, Guillermin P, Boukerrou M, et al. Low clinical burden of 2009 pandemic influenza A (H1N1) infection during pregnancy on the island of La Reunion. PLoS One 2010;5:e10896.

[37] Zhang J, Troendle J, Reddy UM, Laughon SK, Branch DW, Burkman R, et al. Contemporary cesarean delivery practice in the United States. Am J Obstet Gynecol 2010;203:326e1-e10.

[38] Yawn DH, Pyeatte JC, Joseph JM, Eichler SL, Garcia-Bunuel R. Transplacental transfer of influenza virus. JAMA 1971;216:1022-3.

[39] Dulyachai W, Makkoch J, Rianthavorn P, Changpinyo M, Prayangprecha S, Payungporn S, et al. Perinatal pandemic (H1N1) 2009 infection, Thailand. Emerg Infect Dis 2010;16:343-4.

[40] Lieberman RW, Bagdasarian N, Thomas D, Van De Ven C. Seasonal influenza A (H1N1) infection in early pregnancy and second trimester fetal demise. Emerg Infect Dis 2011;17:107-9.

[41] Ortiz JR, Englund JA, Neuzil KM. Influenza vaccine for pregnant women in resourceconstrained countries: a review of the evidence to inform policy decisions. Vaccine 2011;29:4439-52.

[42] Hewagama S, Walker SP, Stuart RL, Gordon C, Johnson PD, Friedman ND, et al. 2009 H1N1 influenza A and pregnancy outcomes in Victoria, Australia. Clin Infect Dis 2010;50:686-90.

[43] Uchide N, Ohyama K, Bessho T, Toyoda H. Induction of pro-inflammatory cytokine gene expression and apoptosis in human chorion cells of fetal membranes by influenza virus infection: possible implications for maintenance and interruption of pregnancy during infection. Med Sci Monit 2005;11:RA7-16.

[44] Shi L, Tu N, Patterson PH. Maternal influenza infection is likely to alter fetal brain development indirectly: the virus is not detected in the fetus. Int J Dev Neurosci 2005;23:299-305. 
[45] McKinney WP, Volkert P, Kaufman J. Fatal swine influenza pneumonia during late pregnancy. Arch Intern Med 1990;150:213-5.

[46] Moretti ME, Bar-Oz B, Fried S, Koren G. Maternal hyperthermia and the risk for neural tube defects in offspring: systematic review and meta-analysis. Epidemiology 2005;16:216-9.

[47] Coffey VP, Jessop WJ. Maternal influenza and congenital deformities. A follow-up study. Lancet 1963;1:748-51.

[48] Hardy JM, Azarowicz EN, Mannini A, Medearis DN, Jr., Cooke RE. The effect of Asian influenza on the outcome of pregnancy, Baltimore, 1957-1958. Am J Public Health Nations Health 1961;51:1182-8.

[49] Saxen L, Hjelt L, Sjostedt JE, Hakosalo J, Hakosalo H. Asian influenza during pregnancy and congenital malformations. Acta Pathol Microbiol Scand 1960;49:114-26.

[50] Edwards MJ. Review: hyperthermia and fever during pregnancy. Birth Defects Res A Clin Mol Teratol 2006;76:507-16.

[51] Hansen C, Desai S, Bredfeldt C, Cheetham C, Gallagher M, Li D-K, et al. A large, population-based study of 2009 pandemic Influenza A virus subtype H1N1 infection diagnosis during pregnancy and outcomes for mothers and neonates. J Infect Dis 2012;206:1260-8.

[52] Luteijn JM, Brown MJ, Dolk H. Influenza and congenital anomalies: a systematic review and meta-analysis. Hum Reprod 2014;29:809-23.

[53] Haberg SE, Trogstad L, Gunnes N, Wilcox AJ, Gjessing HK, Samuelsen SO, et al. Risk of fetal death after pandemic influenza virus infection or vaccination. N Engl J Med 2013;368:333-40.

[54] Pierce M, Kurinczuk JJ, Spark P, Brocklehurst P, Knight M, Ukoss. Perinatal outcomes after maternal 2009/H1N1 infection: national cohort study. BMJ 2011;342:d3214.

[55] Moore DL, Vaudry W, Scheifele DW, Halperin SA, Dery P, Ford-Jones E, et al. Surveillance for influenza admissions among children hospitalized in Canadian immunization monitoring program active centers, 2003-2004. Pediatrics 2006;118:e610-9.

[56] Izurieta HS, Thompson WW, Kramarz P, Shay DK, Davis RL, DeStefano F, et al. Influenza and the rates of hospitalization for respiratory disease among infants and young children. N Engl J Med 2000;342:232-9.

[57] Neuzil KM, Mellen BG, Wright PF, Mitchel EF, Jr., Griffin MR. The effect of influenza on hospitalizations, outpatient visits, and courses of antibiotics in children. N Engl J Med 2000;342:225-31.

[58] Thompson WW, Shay DK, Weintraub E, Brammer L, Bridges CB, Cox NJ, et al. Influenza-associated hospitalizations in the United States. JAMA 2004;292:1333-40. 
[59] Bhat N, Wright JG, Broder KR, Murray EL, Greenberg ME, Glover MJ, et al. Influenzaassociated deaths among children in the United States, 2003-2004. N Engl J Med 2005;353:2559-67.

[60] Thompson WW, Weintraub, E., Shay, D.K., Brammer, L., Cox, N., Fukuda, K. Agespecific estimated of US influenza-associated deaths and hospitalizations. Int Congr Ser 2004;1263:316-20.

[61] Iwane MK, Edwards KM, Szilagyi PG, Walker FJ, Griffin MR, Weinberg GA, et al. Population-based surveillance for hospitalizations associated with respiratory syncytial virus, influenza virus, and parainfluenza viruses among young children. Pediatrics 2004;113:1758-64.

[62] Poehling KA, Edwards KM, Weinberg GA, Szilagyi P, Staat MA, Iwane MK, et al. The underrecognized burden of influenza in young children. $\mathrm{N}$ Engl J Med 2006;355:31-40.

[63] Centers for Disease Control. Surveillance for laboratory-confirmed, influenza-associated hospitalizations-Colorado, 2004-05 influenza season. MMWR Morb Mortal Wkly Rep 2005;54:535-7.

[64] Libster R, Bugna J, Coviello S, Hijano DR, Dunaiewsky M, Reynoso N, et al. Pediatric hospitalizations associated with 2009 pandemic influenza A (H1N1) in Argentina. N Engl J Med 2010;362:45-55.

[65] Fiore AE, Uyeki TM, Broder K, Finelli L, Euler GL, Singleton JA, et al. Prevention and control of influenza with vaccines: recommendations of the Advisory Committee on Immunization Practices (ACIP), 2010. MMWR Recomm Rep 2010;59:1-62.

[66] Centers For Disease Control. Key facts about 2009 H1N1 flu vaccine. http:// www.cdc.gov/h1n1flu/vaccination/vaccine_keyfacts.htm. Published March, 2010. Accessed February 15, 2016.

[67] Ambrose CS, Luke C, Coelingh K. Current status of live attenuated influenza vaccine in the United States for seasonal and pandemic influenza. Influenza Other Respir Viruses 2008;2:193-202.

[68] Centers For Disease Control. General recommendations on immunization: recommendations of the Advisory Committee on Immunization Practices (ACIP). MMWR 2011; 60 (No. 2): 26.

[69] Yudin MH. Risk management of seasonal influenza during pregnancy: current perspectives. Int J Women's Health 2014;6:681-9.

[70] Fiore AE, Shay DK, Broder K, Iskander JK, Uyeki TM, Mootrey G, et al. Prevention and control of seasonal influenza with vaccines: recommendations of the Advisory Committee on Immunization Practices (ACIP), 2009. MMWR Recomm Rep 2009;58:1-52. 
[71] Harper SA, Fukuda K, Uyeki TM, Cox NJ, Bridges CB. Prevention and control of influenza: recommendations of the Advisory Committee on Immunization Practices (ACIP). MMWR Recomm Rep 2004;53:1-40.

[72] Centers for Disease Control. Prevention and Control of Influenza: Recommendations of the Immunization Practices Advisory Committee (ACIP). MMWR Morb Mortal Wkly Rep 2013;62:10, 30.

[73] World Health Organization. WHO recommendations on pandemic (H1N1) 2009 vaccines. http://www.who.int/csr/disease/swineflu/notes/h1n1_vaccine_20090713/en/. July 2009. Accessed November 7, 2015.

[74] Centers For Disease Control. Updated interim recommendations for obstetric health care providers related to the use of antiviral medications in the treatment and prevention of influenza for the 2009-2010 season.http:// www.cdc.gov/h1n1flu/recommendations.htm. December 2009. Accessed January 12, 2016.

[75] Sumaya CV, Gibbs RS. Immunization of pregnant women with influenza A/New Jersey/ 76 virus vaccine: reactogenicity and immunogenicity in mother and infant. J Infect Dis 1979;140:141-6.

[76] Hulka JF. Effectiveness of polyvalent influenza vaccine in Pregnancy. Report of a Controlled Study during an Outbreak of Asian Influenza. Obstet Gynecol 1964;23:830-7.

[77] Deinard AS, Ogburn P, Jr. A/NJ/8/76 influenza vaccination program: effects on maternal health and pregnancy outcome. Am J Obstet Gynecol 1981;140:240-5.

[78] Englund JA, Mbawuike IN, Hammill H, Holleman MC, Baxter BD, Glezen WP. Maternal immunization with influenza or tetanus toxoid vaccine for passive antibody protection in young infants. J Infect Dis 1993;168:647-56.

[79] Zaman K, Roy E, Arifeen SE, Rahman M, Raqib R, Wilson E, et al. Effectiveness of maternal influenza immunization in mothers and infants. $\mathrm{N}$ Engl J Med 2008;359:1555-64.

[80] Manske JM. Efficacy and effectiveness of maternal influenza vaccination during pregnancy: a review of the evidence. Matern Child Health J 2013;18:1599-609.

[81] Black SB, Shinefield HR, France EK, Fireman BH, Platt ST, Shay D. Effectiveness of influenza vaccine during pregnancy in preventing hospitalizations and outpatient visits for respiratory illness in pregnant women and their infants. Am J Perinatol 2004;21:333-9.

[82] Munoz FM, Englund JA. A step ahead. Infant protection through maternal immunization. Pediatr Clin North Am 2000;47:449-63. 
[83] Madhi SA, Cutland CL, Kuwanda L, Weinberg A, Hugo A, Jones S, et al. Influenza vaccination of pregnant women and protection of their infants. N Engl J Med 2014;371:918-31.

[84] Thompson MG, Li D-K, Shifflett P, Sokolow LZ, Ferber JR, Kurosky S, et al. Effectiveness of seasonal trivalent influenza vaccine for preventing influenza virus illness among pregnant women: a population-based case-control study during the 2010-2011 and 2011-2012 influenza seasons. Clin Infect Dis 2014;58:449-57.

[85] Centers for Disease Control. Use of Influenza A (H1N1) 2009 monovalent vaccine: recommendations of the Advisory Committee on Immunization Practices (ACIP). MMWR Morb Mortal Wkly Rep 2009;58:1-8.

[86] Centers for Disease Control. Seasonal Influenza and 2009 H1N1 influenza vaccination coverage among pregnant women-10 states, 2009-2010 influenza season. MMWR Morb Mortal Wkly Rep 2010;59:1541-5.

[87] Horiya M, Hisano M, Iwasaki Y, Hanaoka M, Watanabe N, Ito Y, et al. Efficacy of double vaccination with the 2009 pandemic influenza A (H1N1) vaccine during pregnancy. Obstet Gynecol 2011;118:887-94.

[88] Jackson LA, Patel SM, Swamy GK, Frey SE, Creech CB, Munoz FM, et al. Immunogenicity of an inactivated monovalent $2009 \mathrm{H} 1 \mathrm{~N} 1$ influenza vaccine in pregnant women. J Infect Dis 2011;204:854-63.

[89] Zuccotti G, Pogliani L, Pariani E, Amendola A, Zanetti A. Transplacental antibody transfer following maternal immunization with a pandemic 2009 influenza A(H1N1) MF59-adjuvanted vaccine. JAMA 2010;304:2360-1.

[90] Abzug MJ, Nachman SA, Muresan P, Handelsman E, Watts DH, Fenton T, et al. Safety and immunogenicity of $2009 \mathrm{pH} 1 \mathrm{~N} 1$ vaccination in HIV-infected pregnant women. Clin Infect Dis 2013;56:1488-97.

[91] Yung CF, Andrews N, Hoschler K, Miller E. Comparing the immunogenicity of AS03adjuvanted 2009 pandemic H1N1 vaccine with clinical protection in priority risk groups in England. PLoS One 2013;8:e56844.

[92] Puleston R, Bugg G, Hoschler K, Konje J, Thornton J, Stephenson I, et al. Multi-centre observational study of transplacental transmission of influenza antibodies following vaccination with AS03(A)-adjuvanted H1N1 2009 vaccine. PLoS One 2013;8:e47448.

[93] Moro PL, Broder K, Zheteyeva Y, Walton K, Rohan P, Sutherland A, et al. Adverse events in pregnant women following administration of trivalent inactivated influenza vaccine and live attenuated influenza vaccine in the Vaccine Adverse Event Reporting System, 1990-2009. Am J Obstet Gynecol 2011;204:146e1-7.

[94] Kallen B, Olausson PO. Vaccination against H1N1 influenza with Pandemrix((R)) during pregnancy and delivery outcome: a Swedish register study. BJOG 2012;119:1583-90. 
[95] Pasternak B, Svanstrom H, Molgaard-Nielsen D, Krause TG, Emborg HD, Melbye M, et al. Risk of adverse fetal outcomes following administration of a pandemic influenza $\mathrm{A}(\mathrm{H} 1 \mathrm{N1})$ vaccine during pregnancy. JAMA 2012;308:165-74.

[96] Beau AB, Hurault-Delarue C, Vidal S, Guitard C, Vayssiere C, Petiot D, et al. Pandemic $\mathrm{A} / \mathrm{H} 1 \mathrm{~N} 1$ influenza vaccination during pregnancy: a comparative study using the EFEMERIS database. Vaccine 2014;32:1254-8.

[97] Chambers CD, Johnson D, Xu R, Luo Y, Louik C, Mitchell AA, et al. Risks and safety of pandemic H1N1 influenza vaccine in pregnancy: birth defects, spontaneous abortion, preterm delivery, and small for gestational age infants. Vaccine 2013;31:5026-32.

[98] Heikkinen T, Young J, van Beek E, Franke H, Verstraeten T, Weil JG, et al. Safety of MF59-adjuvanted A/H1N1 influenza vaccine in pregnancy: a comparative cohort study. Am J Obstet Gynecol 2012;207:177.e1-8.

[99] Omon E, Damase-Michel C, Hurault-Delarue C, Lacroix I, Montastruc JL, Oustric S, et al. Non-adjuvanted 2009 influenza A (H1N1)v vaccine in pregnant women: the results of a French prospective descriptive study. Vaccine 2011;29:9649-54.

[100] Tavares F, Nazareth I, Monegal JS, Kolte I, Verstraeten T, Bauchau V. Pregnancy and safety outcomes in women vaccinated with an AS03-adjuvanted split virion H1N1 (2009) pandemic influenza vaccine during pregnancy: a prospective cohort study. Vaccine 2011;29:6358-65.

[101] Richards JL, Hansen C, Bredfeldt C, Bednarczyk RA, Steinhoff MC, Adjaye-Gbewonyo D, et al. Neonatal outcomes after antenatal influenza immunization during the 2009 H1N1 influenza pandemic: impact on preterm birth, birth weight, and small for gestational age birth. Clin Infect Dis 2013.

[102] Simister NE. Placental transport of immunoglobulin G. Vaccine 2003;21:3365-9.

[103] Munoz ET, Deem MW. Epitope analysis for influenza vaccine design. Vaccine 2005;23:1144-8.

[104] Van de Perre P. Transfer of antibody via mother's milk. Vaccine 2003;21:3374-6.

[105] Puck JM, Glezen WP, Frank AL, Six HR. Protection of infants from infection with influenza A virus by transplacentally acquired antibody. J Infect Dis 1980;142:844-9.

[106] Reuman PD, Ayoub EM, Small PA. Effect of passive maternal antibody on influenza illness in children: a prospective study of influenza A in mother-infant pairs. Pediatr Infect Dis J 1987;6:398-403.

[107] Plotkin SA. Correlates of protection induced by vaccination. Clin Vaccine Immunol 2010;17:1055-65.

[108] Coudeville L, Andre P, Bailleux F, Weber F, Plotkin S. A new approach to estimate vaccine efficacy based on immunogenicity data applied to influenza vaccines administered by the intradermal or intramuscular routes. Hum Vaccines 2010;6:841-8. 
[109] Steinhoff MC, Omer SB, Roy E, Arifeen SE, Raqib R, Altaye M, et al. Influenza immunization in pregnancy-antibody responses in mothers and infants. N Engl J Med 2010;362:1644-6.

[110] Yamaguchi K, Hisano M, Isojima S, Irie S, Arata N, Watanabe N, et al. Relationship of Th1/Th2 cell balance with the immune response to influenza vaccine during pregnancy. J Med Virol 2009;81:1923-8.

[111] Lin S-Y, Wu E-T, Lin C-H, Shyu M-K, Lee C-N. The safety and immunogenicity of trivalent inactivated influenza vaccination: a study of maternal-cord blood pairs in Taiwan. PLoS One 2013;8:e62983.

[112] Puleston RL, Bugg G, Hoschler K, Konje J, Thornton J, Stephenson I, et al. Observational study to investigate vertically acquired passive immunity in babies of mothers vaccinated against H1N1v during pregnancy. Health Technol Assess 2010;14:1-82.

[113] Helmig RB, Maimburg RD, Erikstrup C, Nielsen HS, Petersen OB, Nielsen LP, et al. Antibody response to influenza A(H1N1)pdm09 in vaccinated, serologically infected and unaffected pregnant women and their newborns. Acta Obstet Gynecol Scand 2015;94:833-9.

[114] Tsatsaris V, Capitant C, Schmitz T, Chazallon C, Bulifon S, Riethmuller D, et al. Maternal immune response and neonatal seroprotection from a single dose of a monovalent nonadjuvanted 2009 influenza A(H1N1) vaccine: a single-group trial. Ann Intern Med 2011;155:733-41.

[115] Fisher BM, Van Bockern J, Hart J, Lynch AM, Winn VD, Gibbs RS, et al. Pandemic influenza A H1N1 2009 infection versus vaccination: a cohort study comparing immune responses in pregnancy. PLoS One 2012;7:e33048.

[116] France EK, Smith-Ray R, McClure D, Hambidge S, Xu S, Yamasaki K, et al. Impact of maternal influenza vaccination during pregnancy on the incidence of acute respiratory illness visits among infants. Arch Pediatr Adolesc Med 2006;160:1277-83.

[117] Munoz FM, Greisinger AJ, Wehmanen OA, Mouzoon ME, Hoyle JC, Smith FA, et al. Safety of influenza vaccination during pregnancy. Am J Obstet Gynecol 2005;192:1098106.

[118] Benowitz I, Esposito DB, Gracey KD, Shapiro ED, Vazquez M. Influenza vaccine given to pregnant women reduces hospitalization due to influenza in their infants. Clin Infect Dis 2010;51:1355-61.

[119] Landry ML, Cohen S, Ferguson D. Real-time PCR compared to Binax NOW and cytospin-immunofluorescence for detection of influenza in hospitalized patients. J Clin Virol 2008;43:148-51.

[120] Eick AA, Uyeki TM, Klimov A, Hall H, Reid R, Santosham M, et al. Maternal influenza vaccination and effect on influenza virus infection in young infants. Arch Pediatr Adolesc Med 2011;165:104-11. 
[121] McDonald JC, Andrews BE. Diagnostic methods in an influenza vaccine trial. Br Med J 1955;2:1232-5.

[122] Petrie JG, Ohmit SE, Johnson E, Cross RT, Monto AS. Efficacy studies of influenza vaccines: effect of end points used and characteristics of vaccine failures. J Infect Dis 2011;203:1309-15.

[123] Rapmund G, Johnson RT, Bankhead AS, Herman YF, Dandridge OW. The diagnosis of Asian influenza virus infection after recent immunization. U S Armed Forces Med J 1959;10:637-49.

[124] Grist NR, Landsman JB. Influenza in Glasgow, 1950-1953. Glasgow Med J 1955;36:69_ 75.

[125] Anderson SG, Donnelley M, French EL, Kalra SL, White J. Influenza in Victoria, 1950 and 1951. Med JAust 1953;2:44-7.

[126] Poehling KA, Szilagyi PG, Staat MA, Snively BM, Payne DC, Bridges CB, et al. Impact of maternal immunization on influenza hospitalizations in infants. Am J Obstet Gynecol 2011;204:S141-8.

[127] Sugimura T, Nagai T, Kobayashi H, Ozaki Y, Yamakawa R, Hirata R. Effectiveness of maternal influenza immunization in young infants in Japan. Pediatr Int 2015.

[128] Osterholm MT, Kelley NS, Sommer A, Belongia EA. Influenza vaccine efficacy and effectiveness: a new look at the evidence. Lancet Inf Dis, 2012;12:36-44.

[129] Savitz DA, Fell DB, Ortiz JR, Bhat N. Does influenza vaccination improve pregnancy outcome? Methodological issues and research needs. Vaccine 2015;33:6430-5.

[130] World Health Organization. WHO Influenza data taskforce -interim report.2015;1-24.

[131] Kay AW, Blish CA. Immunogenicity and Clinical Efficacy of Influenza Vaccination in Pregnancy. Front Immunol 2015;6:289.

[132] Murray DL, Imagawa DT, Okada DM, St Geme JW, Jr. Antibody response to monovalent A/New Jersey/8/76 influenza vaccine in pregnant women. J Clin Microbiol 1979;10:1847.

[133] Bischoff AL, Folsgaard NV, Carson CG, Stokholm J, Pedersen L, Holmberg M, et al. Altered response to $\mathrm{A}(\mathrm{H} 1 \mathrm{~N} 1)$ pnd09 vaccination in pregnant women: a single blinded randomized controlled trial. PLoS One 2013;8:e56700.

[134] Schlaudecker EP, McNeal MM, Dodd CN, Ranz JB, Steinhoff MC. Pregnancy modifies the antibody response to trivalent influenza immunization. J Infect Dis 2012;206:1670-3.

[135] Sperling RS, Engel SM, Wallenstein S, Kraus TA, Garrido J, Singh T, et al. Immunogenicity of trivalent inactivated influenza vaccination received during pregnancy or postpartum. Obstet Gynecol 2012;119:631-9. 
[136] Patel CG, Phillips Heine R, Staats J, Antczak B, Weaver K, Weinhold K, Swamy C. Tfollicular helper (Tfh) cell expansion varies by trimester after influenza vaccination in pregnancy. AJOG,2016;214:S57-S58.

[137] Sullivan SG, Komadina N, Grant K, Jelley L, Papadakis G, Kelly H. Influenza vaccine effectiveness during the 2012 influenza season in Victoria, Australia: Influences of waning immunity and vaccine match. J Med Virol 2013;86:1017-1025.

[138] Kissling E, Valenciano M, Larrauri A, Oroszi B, Cohen JM, Nunes B, et al. Low and decreasing vaccine effectiveness against influenza A(H3) in 2011/12 among vaccination target groups in Europe: results from the I-MOVE multicentre case-control study. Euro Surveill 2013;18.

[139] Rasmussen SA, Watson AK, Kennedy ED, Broder KR, Jamieson DJ. Vaccines and pregnancy: past, present, and future. Semin Fetal Neonatal Med 2014;19:161-9.

[140] van der Maas N, Dijs-Elsinga J, Kemmeren J, van Lier A, Knol M, de Melker H. Safety of vaccination against influenza $\mathrm{A}(\mathrm{H} 1 \mathrm{~N} 1)$ during pregnancy in the Netherlands: results on pregnancy outcomes and infant's health: cross-sectional linkage study. BJOG 2015.

[141] Sobanjo-Ter Meulen A, Abramson J, Mason E, Rees H, Schwalbe N, Bergquist S, et al. Path to impact: A report from the Bill and Melinda Gates Foundation convening on maternal immunization in resource-limited settings; Berlin-January 29-30, 2015. Vaccine 2015;33:6388-95. 
